\title{
How to measure public demand for policies when there is no appropriate survey data?
}

\author{
BIANCA OEHL \\ Center for Comparative and International Studies (CIS), ETH Zurich, Switzerland \\ E-mail: bianca.oehl@gmail.com
}

\author{
LENA MARIA SCHAFFER \\ Department of Politics and Public Administration, University of Konstanz, Germany \\ E-mail: lena.schaffer@uni-konstanz.de \\ THOMAS BERNAUER \\ Center for Comparative and International Studies (CIS), ETH Zurich, Switzerland \\ E-mail: thbe0520@ethz.ch
}

\begin{abstract}
Explanatory models accounting for variation in policy choices by democratic governments usually include a demand (by the public) and a supply (by the government) component, whereas the latter component is usually better developed from a measurement viewpoint. The main reason is that public opinion surveys, the standard approach to measuring public demand, are expensive, difficult to implement simultaneously for different countries for purposes of crossnational comparison and impossible to implement ex post for purposes of longitudinal analysis if survey data for past time periods are lacking. We therefore propose a new approach to measuring public demand, focussing on political claims made by nongovernmental actors and expressed in the news. To demonstrate the feasibility and usefulness of our measure of published opinion, we focus on climate policy in the time period between 1995 and 2010. When comparing the new measure of published opinion with the best available public opinion survey and internet search data, it turns out that our data can serve as a meaningful proxy for public demand.
\end{abstract}

Key words: climate policy, Google Trends, political claims analysis, public demand, public opinion survey

\section{Introduction}

Systematic measurement of public demand - that is, the aggregate of what individuals in a given society prefer or want - plays an important role in most political systems, most of all in democratic political systems, where the political survival of members of parliament and government depends on 
electoral support. This makes accurate measurement of public demand important, both from the perspective of policymakers and the public. In this article, we propose an alternative way to measure public demand when survey data are not available. We add to the debate of measuring public demand by providing comparisons with established demand measures.

Besides the aforementioned normative and political considerations, measurement of public demand is also important from an academic viewpoint. Standard theories of democratic policymaking argue that, some principal-agent problems notwithstanding, political decisionmakers generally supply public policies demanded by the median voter and/or pivotal interest groups. As Dahl noted, "A key characteristic of democracy is the continued responsiveness of the government to the preferences of the people" $(1971,1)$. The supply side of policymaking is, in most cases, quite easily observable in empirical research. That is, researchers can study statements of policymakers (e.g. in parliament or public speeches) and they can observe and code political decisions that are taken, as well as the related policy output (e.g. new laws, regulations and government spending).

The demand side is more difficult to observe and measure independently from policy supply (policy output) and is arguably more complex from a conceptual perspective. In our view, very well-designed public opinion surveys can serve as the "gold standard" for measuring public demand in particular policy areas. Although many surveys nowadays meet such standards, the most important shortcoming concerns the availability and commensurability of data. ${ }^{1}$ Because of high costs and changing research interests, public opinion survey data in virtually any area of public policy are largely incomplete. That is, they provide snapshots of public opinion at specific points in time within one, or at best in a few, countries. "Stitching" together different survey data sets is in some cases possible, but remains highly problematic (see further below) - for example, because of differences across surveys in design and item wording. ${ }^{2}$ Most fundamentally, however, filling gaps ex post is impossible.

${ }^{1}$ In the climate policy area, Brewer (2005) and Nisbet and Myers (2007) provide an overview of United States (US) surveys and Brechin and Bhandari (2011) an overview of multinational surveys. Two major commensurability problems concern survey item wording and differences in language and items in multinational surveys. For instance, survey experiments for the US show that even minor differences, such as using either "global warming" or "climate change", in survey items can have an effect on responses (Luntz 2003 as cited in Lakoff 2010, 71). Multinational surveys, each of which is implemented in a different language, face even greater commensurability problems.

${ }^{2}$ In the climate policy area, recent research has combined data from different surveys to create times series (Brulle et al. 2012). This approach has been used only for the US for the 1990-2012 time period, and for very few survey items (mainly items measuring concern over climate change, 
In modern democracies, however, the media system acts as an important intermediary between citizens and policymakers. It provides a platform on which stakeholders voice and spread their views and demands, and where citizens obtain information on policy-relevant societal problems and possible solutions. "[C]ivic initiatives and social movements can influence policymakers only if they are able to achieve visibility in the mass media" (Koopmans 2007, 184). Likewise, politicians use media reporting to gauge the public mood regarding specific policy issues (Herbst 1993; Powlick 1995; Mutz 1998), because they face the same problem of nonavailability or other limitations of survey data (Jacobs and Shapiro 2000). This makes media content a valuable information source for measuring public demand, both in terms of assessing public opinion and in establishing the saliency of a particular issue. We propose that, especially by excluding statements from government officials and concentrating on claims made by nongovernmental actors, media content analysis can serve as a valid proxy in trying to measure general public demand when it is impossible to rely on commensurable data from public opinion or stakeholder surveys across time and space.

Our objective in measuring public demand is to ultimately test the influence demand has on policymaking. However, to build explanatory models for the supply side, we first need better measures of crosscountry variation on the demand side. To this end, we need to focus on the component of demand that is actually public, meaning that it can be observed by politicians. Media reporting fulfils this requirement, as it is observable for politicians on a regular basis. Even though opinions reflected in media discourse might be elite driven, we argue that politicians have limited time and resources to actually poll people regularly on different issues, and thus have to rely on the daily media discourse as a proxy for public opinion.

In this article, we argue that media content analysis can provide us with a useful measurement of public demand when it is impossible to measure it via public opinion surveys. We then assess whether our media-based measures can serve as valid proxies for public demand. Our substantive focus in this article lies in the measurement of demand for climate change policy. Future research could then use the new demand measure to explain the supply of climate policies across countries.

We chose climate change, which is a moderate-to-low salience topic in most countries (relative to other policy issues on national agendas) within our time period of analysis (1995-2010). Climate change is a rather new 
issue on most governments' agendas and, in surveys on what people consider the most important problem (MIP) of their respective countries, it is usually not placed very high up on the list. Furthermore, climate change issues do not, in most countries, play a prominent role in electoral competition. As a consequence, measuring public demand concerning this issue via survey data is even more challenging, given that adequate survey data are scarcer, compared with higher-salience issues such as welfare state or taxation policy. More salient issues have been standard items in public opinion surveys for a long time (Burstein 2003). However, scholars such as Burstein $(2003,2006)$ argue that, for example, studies on the responsiveness of government to public demand may suffer from confirmatory biases if they are based solely on items in public opinion surveys that by design overwhelmingly ask questions about highly salient topics. We thus add to the literature by introducing media content analysis as a way to measure public demand also for low- or medium-salience issues.

We first introduce new data on political claims presented in the media for or against climate policy in the time period between 1995 and 2010. We then examine whether such data can serve as a useful proxy for public demand in this policy area.

Although our new media-based data set covers six countries so far, we restrict detailed comparison to the US, and corroborate our results for two more countries, Spain and Germany. ${ }^{3}$

The US is the only country for which public demand measures for climate change policy exist from three alternative sources, which allows for a systematic comparison over time. These alternative sources are opinion surveys whose data were combined using a method developed by Stimson (1999) to measure the policy mood- the climate change threat index (CCTI), Gallup's MIP question and data from Google Trends measuring internet searches. Comparison of our new claims data with survey data and Google Trends data on climate change shows that media analysis can serve as a valid proxy for most aspects of public demand. Finally, to increase confidence in the generalisability of our measurement approach, we offer a further comparison of our claims data with survey data, although with less detailed questions targeted at climate change, and Google Trends data for two more countries - Germany and Spain.

\footnotetext{
${ }^{3}$ Inherent to the problem concerning survey items on climate change described in the introduction is of course that there are indeed few public opinion surveys with which to compare and corroborate our own measure. Also, these few survey samples - although all to some extent randomly drawn from the population - have no panel data and can only very cautiously be interpreted as dynamically representing the "true" public opinion.
} 
The remainder of this article is structured as follows. In the next section, we discuss in more detail the relevance of public demand for policymaking as well as previously used demand measures. We then discuss our concept and our operationalisation of public demand. After a presentation and discussion of established demand measures, we compare them with our demand measures in the following section. We subsequently present a further reliability check, focussing on data from two more countries, Germany and Spain. We end with an outlook on how our approach and the resulting data can be used to measure public demand.

\section{Public demand and politics}

Theoretically, public policy scholars hold different views on which "workhorse" models of public policymaking offer more robust explanations of policy choices. Those models differ significantly in terms of what types of demand are most relevant. On the one hand, the median voter model (Downs 1957) presumes that voters have single-peaked preferences and public demand can somehow be aggregated into a single dimension, and that the voter in the middle of an observable distribution is at the centre of attention from the policymakers' perspective. On the other hand, interest group models agree that the median voter matters, but they also claim that in many cases interest groups facing large and concentrated opportunity costs and/or benefits are easier to organise and are likely to fight harder to get what they want, relative to more latent interests in society(Olson 1965; Persson and Tabellini 2002). Empirically, these two basic models of democratic policymaking have different implications for the classical measurement of demand for policies. In the following sections, we will introduce classical measurements of different facets of demand and briefly elaborate on their main advantages or shortcomings.

Scholars seeking to explain policy choices from an interest group perspective usually engage in stakeholder surveys. Such surveys measure the preferences of stakeholders (e.g. interest groups), their position within policymaking networks and their self- or other-assessed influence on public policy (Fisher et al. 2012). Scholars seeking to explain policy choices from a median voter model perspective tend to rely either on simple structural proxies, on public opinion survey data or - more recently - on internet search data.

With respect to structural proxies for public demand, in studies on environmental policies, many scholars rely on Gross Domestic Product (GDP) per capita, arguing that at low levels of income people prefer economic growth over environmental protection and that, at some point, this trend reverses and people demand more postmaterial goods such as environmental protection (Dasgupta et al. 2002; Bättig and Bernauer 2009; Spilker 2011; Kim and WolinskyNahmias 2014). Similarly, levels of democracy are presumed to be associated 
with stronger public demand for environmental public goods provision (Neumayer 2002; Bättig and Bernauer 2009). Other studies have used environmental Non-governmental organization (NGO) density (Bernauer et al. 2010), NGO counts (Frank 1999; Fredriksson and Millimet 2004; Roberts et al. 2004) and share of green parties in the legislature (Neumayer 2003) as proxies for public demand.

However, to explain policy output in many countries over time, we are in need of more direct measures of public demand without having to rely, for instance, on the assumption that the theoretical linkages stipulated by the environmental Kuznets curve (Dasgupta et al. 2002; Bernauer and Schaffer 2012) hold true.

As stated before, well-designed and executed public opinion surveys can be regarded as the gold standard when seeking to capture public demand. Thus, the fact that public opinion is measured directly from the source is the main advantage of public opinion surveys. However, the main problem with existing survey data is that they fail to provide consistent time series data for longer periods and that they do not fully cover the various dimensions of policy problems. These limitations exist even more for questions regarding climate change policy. Although the issue has gained some prominence for the latter part of the time period and for advanced industrialised countries (with extensive survey activity particularly in the US), it still cannot be compared with more salient topics such as pensions or the welfare state in general.

\section{Internet searches}

Increasing use of the internet is generating enormous amounts of metadata. Such data, to the extent that they are accessible, can be used to infer the salience of specific policy issues. Google Trends provides data on web searches for all search terms that pass a minimum threshold of requests (Google 2014). The Google Trends data are available for most industrialised countries from 2004 onwards. We use such search request information for the terms global warming and climate change to obtain a proxy for the saliency of the climate change issue.

Data provided by Google Trends are increasingly being used for research (Kahn and Kotchen 2011; Scharkow and Vogelgesang 2011; Choi and Varian 2012; Pelc 2013). It directly measures information-seeking behaviour in the field (Scharkow and Vogelgesang 2011, 106). For instance, Kahn and Kotchen (2011) find that higher unemployment led to fewer Google searches for "global warming" and more searches on "unemployment". This result suggests a crowding-out effect, meaning that people are either interested in climate change or unemployment, but not both at the same time.

Some preliminary comparisons of Google Trends, news reporting and survey data have already been undertaken. Mellon (2014) examines the 
relationship between Google searches and survey results. He examines whether Google Trends data can act as a proxy for the salience of seven issues, in comparison with survey responses to the MIP item of Gallup. For four of the seven issues, the Google search data and the Gallup survey data correlate significantly. Ripberger (2011) compares news coverage of global warming, terrorism and healthcare in the New York Times with Google searches. He finds that Google searches Granger cause the media reporting, and, when turned around, media reporting also Granger causes Google searches for two of the three issues.

In this article, we therefore propose to use media content analysis to measure general public demand when it is impossible to rely on data from these more traditional measures (public opinion, stakeholder surveys or internet searches). Furthermore, besides reasons of availability, we are also convinced that media reporting data can combine the two theoretical perspectives (interest group and median voter) and help us learn more about public demand for particular policies within a country. In the next section, we take a look at the relationship between media, public demand and policymakers.

\section{Public demand and the media}

Often, the relationship between politics, the media and the public is depicted using a triangle (Bernauer et al. 2014). We follow this notion with our assumption that direct interactions between public and politics can happen, but that most of the interactions happen indirectly through an intermediary actor - the media. On the one hand, the media reflects viewpoints of politicians and parties in the form of interviews and reports, and, on the other hand, also channels the interests of ordinary citizens and other nonstate actors.

Organised interest groups often make their demands public in a way that ensures media attention (e.g. the animal protection organisation People for the Ethical Treatment of Animals (PETA) uses naked celebrities to raise awareness on the issue of fur). Newspapers give their (average) readers space to express opinions in the form of letters to the editor and other commentary sections. In addition, all media outlets provide some form of "comment", where journalists give their personal opinion on relevant topics. Thus, the media presents a rich and multifarious sample of opinions and demands. In this study, we build on this in order to create our proxy for the general public demand on a particular topic.

The scholarly community on media effects thus scrutinises one direction of the aforementioned triangle: the effect of media on public opinion. With regard to demand, however, media studies have traditionally 
emphasised the salience component of public demand (Weingart et al. 2000; Brossard et al. 2004; Carvalho and Burgess 2005; Boykoff 2007; Boykoff and Mansfield 2008; Ahchong and Dodds 2012; Schmidt et al. 2013). Studies on media impact, for instance, agenda-setting theory (McCombs and Shaw 1972; McLeod et al. 1974), argue that one principal role of the media is to communicate to people what topics to think about. Empirically, salience is usually measured by frequency of reporting and placement (Andrewsa and Caren 2010).

Although salience is relatively easy to measure empirically and quite uncontroversial at the conceptual level, the concept of opinion is more challenging. Proponents of agenda-setting theory postulate that the media shapes what issues people think about, but that it does not necessarily have a strong influence on their opinions per se. Other media researchers such as Zaller (1992) argue, however, that the media actually influence public opinion. Krosnick et al., for instance, note that "media coverage sometimes increases national seriousness assessments by altering existence beliefs, sometimes by conferring knowledge and thereby increasing certainty, or sometimes by altering people's perceptions of a phenomenon's consequences" $(2006,36)$. With respect to our substantive issue interest climate change policy - some studies show that media usage positively affects knowledge and awareness on several aspects of climate change (e.g. causes, possible solutions, see Stamm et al. 2000; Krosnick et al. 2006; Zhao 2009). Several studies find evidence for effects of media content on public opinion (Gamson and Modigliani 1989; Vliegenthart et al. 2008; Sampei and Aoyagi-Usui 2009). For example, Vliegenthart et al. (2008), in a study covering nine countries, find that media reporting that highlights benefits is positively correlated with support for the European Union (as measured by surveys), and reporting on contested issues is negatively correlated with support. Overall, this research shows that published opinion, the aggregate of opinions represented in the media, and public opinion, as measured by surveys, are not identical.

This comes as no surprise given our above-mentioned arguments that media reporting also reflects claims and opinions of interest groups and not solely the general public. However, by affecting knowledge and awareness, the two phenomena (published opinion and public opinion) arguably are related, and thus, for our purposes, to find a general demand measure that can ultimately serve to explain policymaking, the multifarious published opinion is more relevant than the survey-based public opinion. Moreover, as the omnipresent published opinion is (compared with opinion polling) rather easily available, we claim that this demand measure is likely to be observed closely by policymakers (Herbst 1998). 
Even though it remains unclear how much direct influence the media has on public opinion (Habel 2012; Lee 2014), most researchers agree that at least indirect effects exist. One such indirect effect is likely to be that "people will tend to overestimate the influence mass communications have on the attitudes and behavior of others" (Davison 1983, 3). This is called the third-person effect. Empirically, the third-person effect is well documented (Perloff 1993; Sun et al. 2008). Gunther (1998), for example, showed in an experiment that the slant of news reporting causes differences in perceived public opinion by the participants: although the participants did not change their own opinion on their respective topics, they expected that others had changed their opinion because of the reporting. Policymakers who are interested in the current state of public opinion rely on the media exactly for that reason (Herbst 1998, 86). They also face the problem of insufficient survey data. Herbst $(1993,101)$ reports that, in the 1930s and 1940 s, $86 \%$ of congressmen relied on the printed press to gauge public mood, and a quarter of congressmen actually counted newspaper editorials to get insights into opinion on specific topics. As outdated as this finding might seem at the first glance, more recent research supports this result (Herbst 1998). It is the "influence of presumed influence" (Gunther and Storey 2003) that matters - for politicians as well. For example, policymakers try to get access to and coverage in the media to present themselves in a good light because they believe that their media coverage influences their reelection chances (Cohen et al. 2008). A prerequisite for that expectation is that politicians believe in the influence the media has on public opinion. Politicians even take specific news reports as a call for action (Cook et al. 1983; Herbst 1998, 79). However, "it is the totality of media attention, the general slant or tendency of coverage (...) that is synonymous with public opinion" for them [Herbst 1998, 67 (emphasis in original)].

Much like politicians, we can therefore rely on media content analysis to generate high-frequency data for public demand that can also be used to reconstruct public demand backwards in time - which is impossible with public opinion surveys. Our content analysis follows this idea by looking at frequencies and claims, which are opinion statements of nongovernmental actors in the news, in order to grasp what is discussed by the public. Various authors have argued that these claims influence public opinion the most (Koopmans 2004; Howland et al. 2006). Our assumption is that claims are those parts of media content that reflect the perceived published opinion best. $^{4}$

\footnotetext{
${ }^{4}$ However, as outlined below in more detail, we only use the claims as the basis for our demand measure. Although we rely on claims to construct our opinion measure, we do not use what is typically known as the claims analysis approach [e.g. of claims analysis, see Koopmans
} 
As we established above, the published opinion is likely to differ from public opinion measured by surveys. Furthermore, in contrast to large parts of the media effects literature (McCombs and Shaw 1972; Zaller 1992), we are not interested in trying to explain whether public opinion shapes news media reporting and the published opinion, or vice versa. Hence, if it would turn out that survey results change first and public opinion follows suit, this would still be perfectly in line with our expectations as we only want to show that the relationship exists, independent of its direction. However, public opinion remains hidden and abstract most of the time. Politicians who try to gauge the public demand for certain policies must therefore rely on what is available - which is mostly the published opinion. Published opinion consists of single opinions made public through the media, and can also be described as elite opinion, as it results from a selection process by journalists. $^{5}$

\section{The public demand spectrum}

In developing an empirical measure of the general public demand, we need to disentangle the theoretical dimensions of the concept we are interested in. We consider public demand as a multifaceted umbrella term. Public demand towards a topic is composed of a salience and an opinion component (see Figure 1). Salience captures how important a given issue is from the viewpoint of members of a given social unit (e.g. a country). Empirical demand measures combine the two elements - salience and opinion - in varying ratios. In the communication sciences, for instance, "[e]mpirically, object salience on the media agenda typically is measured by the amount of media coverage over time" (Chyi and McCombs 2004, 22). In survey research, respondents are often confronted with a list of social problems and are asked to rank these problems in terms of how important they think these are.

Opinion is located on the other axis and captures the position people take about a given social problem, what they think should be done about it and by whom. The ends of the spectrum are distinct in the sense that individuals or

and Statham (1999) and Koopmans (2007)]. Claims analysis aims to identify networks of claimmakers, for example, to test for Europeanisation (Koopmans and Statham 2010, 55). In our approach, we are less interested in the claimmaker (and e.g. do mostly exclude government officials) and rather want to scrutinise the content of the claims made. Thus, although traditional claims analysis does not exclude government officials, they only measure the topic but not whether the claimmaker is in favour or against it - in contrast, this is the key element of our approach.

${ }^{5}$ However, as we argue below, by including letters to the editor, we can ameliorate this bias to a certain extent. 


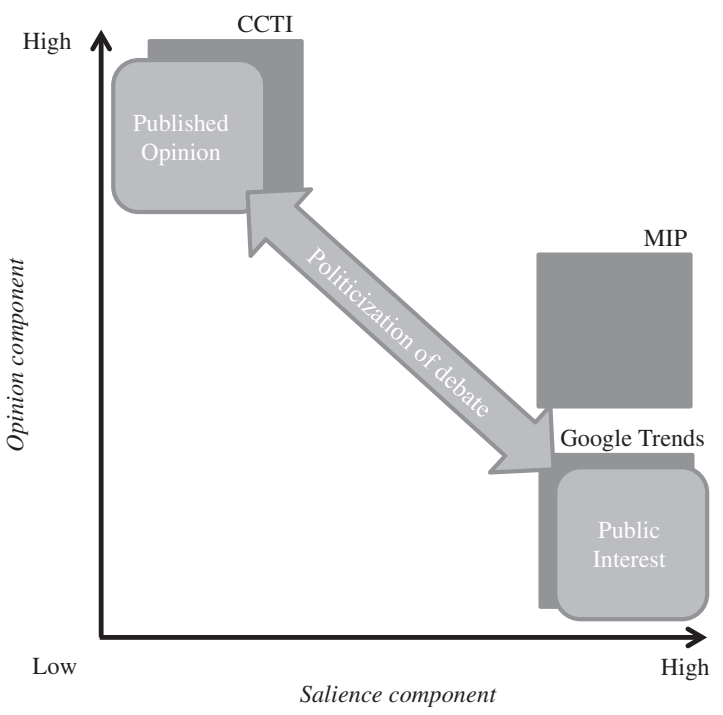

Figure 1 Spectrum of public demand with the three media-based demand concepts. Note $:$ CCTI = climate change threat index; MIP = most important problem.

groups that make up the general public may hold opinions on a given issue, whereas the underlying issue may or may not be important to them.

We propose three measures: media salience, politicisation of the public debate and published opinion. These can all be placed at different points of the demand spectrum. As the name indicates, our media salience measure represents the salience aspect of demand, whereas we capture the opinion aspect of demand via published opinion in our data.

Politicisation of the public debate covers the middle ground between salience and opinion on the public demand spectrum by combining the extent of coverage of the topic as well as the specific opinions presented. Politicisation thus provides information on how contested or politicised the respective issue is within the media debate. ${ }^{6}$ In contrast to the positive (pro) and negative (con) directionality of the published opinion measure, politicisation accounts for the general level of debate that exists over the topic of interest. Thus, a politicised debate can be characterised by a high number of opinionated (pro or con) statements on a certain topic presented within the public discourse.

${ }^{6}$ The terms salience and opinion have a dual function: They describe the two ends of the demand spectrum but also serve as the names for two of our three concepts. To avoid confusion, the measures, respectively the variables, are written in italics. 
Although we may observe times where factual coverage of the issue is high (thus resulting in a high media salience for the issue) and times when there are only a few articles - but these are full of positive or negative claims for policy change from the government (thus, resulting in a high positive or negative published opinion towards climate change policies), the politicisation measure is able to distinguish whether for a given salience of the topic there is more debate (i.e. more pro or constatements). The politicisation measure thus proxies how contested a debate is in terms of statements given (independent of their direction). ${ }^{7}$

We compare our measures with existing public opinion survey data and data from Google Trends - a new data source that is increasingly used in social sciences research.

The next section starts with a discussion on the relationship between media, opinion and politicians, presents the data generated by our newspaper content analysis and subsequently offers a brief description of the public opinion survey data and the internet search requests data we use for the comparison.

\section{Measuring public demand in the media}

This section describes the coding of our theoretically established dimensions of public demand - media salience, published opinion and politicisation - by means of a media content analysis. The latter measure combines salience and opinion by capturing the politicisation of public debate in terms of the relative frequency of claims (pro or con) in comparison with the frequency of media reporting on climate change issues. Future research will have to establish which of these three demand measures performs best in the sense of explaining and predicting policy output over time and across countries. In any event, the politicisation measure is the most encompassing as it includes both the salience and opinion component of public demand.

\section{Sample and coding procedure}

For media content analysis in the US, we selected USA Today and the New York Times. ${ }^{8}$ In introducing our data in the descriptive part, we

${ }^{7}$ A further measure in terms of the public debate concerns the scope of the debate, and thus the conditional effect of published opinion for differing levels of salience. We do not explicitly deal with this measure here, as it solely describes a linear combination of our salience and opinion measures. However, we submit that for an analysis of policy responsiveness, the interaction between salience and opinion needs to be taken into account and give us further insights into how the political debate on a given issue evolves and influences policymaking.

${ }^{8}$ The media content analysis was carried out for six Organisation for Economic Co-operation and Development (OECD) countries: Canada, Germany, Italy, Spain, Switzerland and the US. 
present the two newspaper series separately for the reader to grasp the particularities of each media outlet. However, as both newspapers together reflect the media landscape more appropriately, we combined the values for our comparative analysis. There are three main reasons for using daily newspapers and particularly newspapers of record. First, they serve as agenda setters for other media such as television, radio, internet and other newspapers (Golan 2006; Vliegenthart and Walgrave 2008; Denham 2014). Journalists read news to determine what "news" is. Even for new media such as blogs, a close, reciprocal relationship with regard to agenda setting between newspapers and blogs exists (Wallsten 2007). This means that newspapers of record can serve as a good proxy for the general media landscape. Second, newspapers have more capacity than, for example, TV news for reporting on political topics that are currently less prominent. In addition, newspaper reporting has a longer durability. Newspaper articles can be easily forwarded (also through social networks) and print versions last at least 24 hours, whereas in broadcasting the composition of news can change every hour (Herbst 1998, 85). Third, as we were looking for a demand measure with high transferability potential, we chose a data source that is easily accessible.

We relied on online archives to download all articles relevant to the climate change issue from 1995 to 2010 (see Appendix A for more information on the search terms and download procedure). We covered the full reporting of each newspaper. The only sampling that took place was based on the requirement that at least five climate change (policy)-related keywords had to be present. To ensure replicability, the coding was based on a project language approach (Peter and Lauf 2002). This means that all articles were mostly read and coded by native speakers, although the codebook was written in the project language (English), and all reliability tests and training were also conducted in English. In total, nine research assistants were involved in the coding process. ${ }^{9}$ In the remainder of this section, we briefly describe how each of the three measures is defined and

For reasons noted at the outset, we restrict the analysis in this article to the US. The data coding was done for two national newspapers (conservative and liberal) per country for the time period 1995-2010 (see Table A1 in Appendix A).

${ }^{9}$ For the reliability tests, several test scores were estimated. The values for Krippendorf's $\alpha$, a measure for intercoder reliability, were obtained via a comparison of the research assistants' coding with the master coding of 63 articles, giving the following value ranges. Policy: $0.8-0.89$, subnational: $0.57-0.82$, opinion piece: $0.89-0.95$, claim: $0.55-0.7$, relevance: $0.92-0.96$, theme: $0.81-0.85$. After the reliability coding, the research assistants were again trained on the values with less than 0.7. Two research assistants who failed the absolute minimum threshold of 0.5 received further individual training and reached the same levels with a second reliability test. These scores are in line with reliability scores reported in other content analysis studies (Brossard et al. 2004; Howland et al. 2006). 
coded and present the resulting data descriptively (for additional information, see Appendix A). As we recorded the exact publication date for each article, the smallest time unit is the day. However, to compare our new media data with public opinion survey data, we aggregated our data either to the monthly or to the quarterly level.

\section{Media salience}

To measure media salience, we use the number of climate change-related (see Appendix A for definition) articles relative to the total number of articles published in the respective newspaper within a given time. Figure 2 displays the resulting data for the two newspapers from which the data for the US were coded.

It is noteworthy that the two series parallel each other quite closely with similar peaks. Five events coincide with (and are presumably causing) spikes in our media salience measure: the signing of the Kyoto Protocol in December 1997; the conference of the parties in Bonn in July 2006; the publication of the 4th assessment report of the Intergovernmental Panel on Climate Change (IPCC) in March 2007; and the Conference of the Parties in Bali in December 2007 and in Copenhagen in December 2009 (see also Sampei and AoyagiUsui 2009; Schaffer 2011). We also observe a strong upward trend in media salience from about 2005 to 2009.

We will compare media salience to Google Trends and MIP, as these are the two most established indicators that reflect salience. Hence, the fit should be best among these three measures (see below for a detailed discussion of the reference demand measures).

\section{Published opinion}

Assuming that debate in the media reflects the distribution of published opinion, we have coded claims in favour (for more climate protection) or against (preservation of the status quo or less climate protection). In general, claims are statements, demands or opinions given by an individual or an organisation or summaries of position papers, press statements, comments and so on. In addition, a claim is always directed towards the future and at something that lies beyond the sphere of influence of the claim maker. This means that claims by government officials have not been recorded. To the contrary, a major share of our claims stems from letters to the editor written by ordinary citizens, as we do not differentiate by claim maker. With regard to our definition of claims, we deviate from the classical claims analysis approach by Koopmans and Statham (1999). This adaptation is necessary, as we pursue a different goal with our claims data. In fact, for our purpose, claims are an intermediate, and only their direction and frequency are examined. 


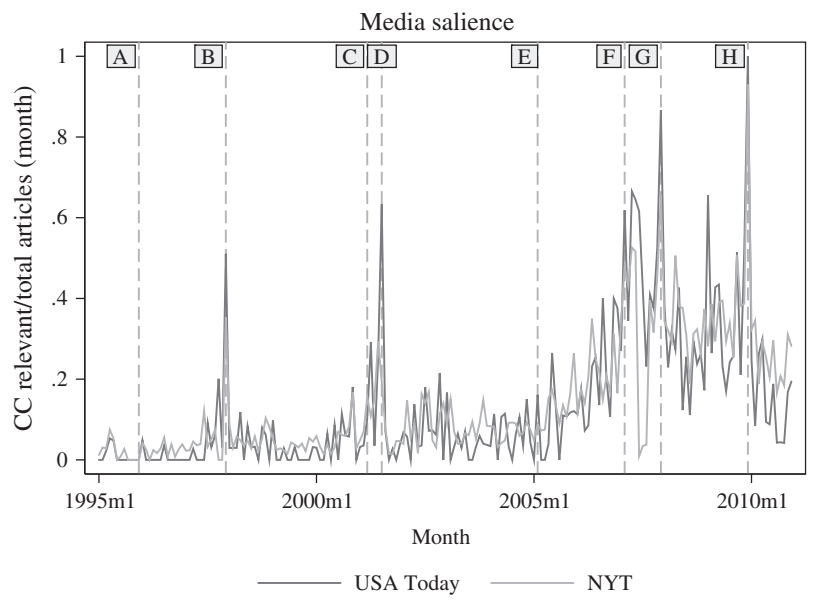

Figure 2 Media salience of the climate change (CC) issue, 1995-2010, monthly data.

Note: Measured as the number of CC-relevant articles as a proportion of all articles published within a given month in the USA Today and the New York Times (NYT). Scale $=0 \ldots 1$, where 1 is the empirical maximum of the variable (occurs in 2009m12). Events: A: IPCC assessment report 2 (AR2) (1995m12); B: Conference of the Parties (COP) Kyoto (1997m12); C: AR3 and United States withdrawal from the Kyoto Protocol (2001m3); D: COP Bonn (2001m7); E: Kyoto Protocol enters into force (2005m2); F: AR4 (2007m2); G: COP Bali (2007m12); and H: COP Copenhagen $(2009 \mathrm{~m} 12)$.

Claims can be either general or specific. For the pro claims, this can look like, respectively, "The major countries that emit should take domestic action, and not have these loopholes" and "We need a moratorium on coal now". ${ }^{10}$ The same applies to con claims: "This [limit on greenhouse gas emissions for the industry] has the potential to be very damaging to the California economy" and "For years, Dr. Goklany, an electrical engineer by training, has written in papers and books that it may be better not to force cuts in greenhouse gases because the added prosperity from unfettered economic activity would allow countries to exploit benefits of warming and adapt to problems". ${ }^{11}$

${ }^{10}$ Published in USA Today, 22 November 2000, p. 27A, "U.S. blasted in talks over global warming Europe assails treaty loopholes on gas emissions" and the New York Times, 23 April 2008, p. 1, "Europe Turns to Coal Again, Raising Alarms on Climate Change”.

${ }^{11}$ Published in USA Today, 1 September 2006, p. 6B "California business leaders say emissions limit could harm economy" and the New York Times, 29 January 2006, p. 1, "Climate expert says NASA tried to silence him". 


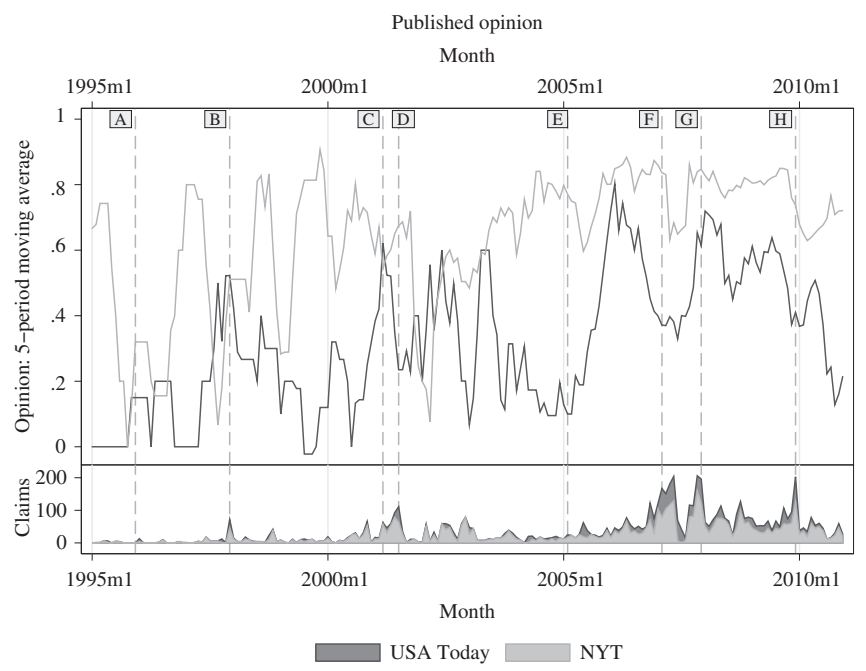

Figure 3 Published opinion (ratio of pro- and con climate protection claims over total claims), 1995-2010, five-month moving average.

Note: Measured as pro- minus con climate protection claims divided by the sum of positive and negative (total) claims per month. Scale $=-1 \ldots 1$; where " -1 " means that only negative claims were made and " 1 " that only positive claims were made. Using five-months moving averages makes it easier to visually compare the two series. Events: A: assessment report 2 (AR2) (1995m12); B: COP Kyoto (1997m12); C: AR3 and United States resigns of Kyoto (2001m3); D: COP Bonn (2001m7); E: Kyoto Protocol in force (2005m2); F: AR4 (2007m2); G: COP Bali (2007m12); and H: COP Copenhagen $(2009 \mathrm{~m} 12)$. NYT $=$ New York Times.

We use the ratio of pro and con claims, defined as pro minus con claims divided by the total number of claims, as our published opinion measure. This measure captures whether news media content within a given time interval is leaning more for or against climate protection. Figure 3 displays the data generated by this approach for the New York Times and USA Today. The upper panel shows the five-month moving average of our published opinion measure, whereas the lower panel gives information on the actual number of claims made in the respective newspaper at a given point in time.

As one might expect, there is less similarity between the two newspapers, compared with the salience measure, as this measure taps more into editorial preferences of the newspaper and how certain issues and positions of stakeholders are reported. Contrary to the media salience measure, the two series do not move in parallel. The New York Times has the largest proclimate protection claims peak in 2001 (probably in view of US withdrawal from the Kyoto Protocol), and, from about 2004 onwards, includes on 
average more pro climate claims in relation to total claims than USA Today. The rough shape of the time series in earlier years stems from the lower absolute number of claims. There is a general upwards trend in the pro climate protection claims ratio for the 1995-2009 period.

As discussed above, we do not expect that published opinion correlates perfectly with public opinion measures. However, we do expect that our measure of published opinion and the two survey-based measures CCTI and MIP should at least generally move into the same direction. Nevertheless, we want to stress that other survey items asking people whether, for example, the government should do more on climate change would be more directly comparable with our more detailed measure.

\section{Politicisation of the public debate}

Although the media salience measure captures the attention climate change issues receive in the media in general terms, it does not really measure how intense or contested the public debate on the subject is. We submit that the total numbers of claims (positive and negative) in relation to salience can proxy for debate intensity, or politicisation, of the issue. This measure includes both salience and opinion, and thus offers a rather encompassing measure of public demand.

We use the total number of claims (both pro and con climate protection) divided by the total number of climate change-relevant articles in a given time interval to that end. Figure 4 displays the resulting data. Similar to the salience measure, the two series move quite closely in parallel. Furthermore, the overall level of politicisation rises over time.

As stated above, this novel concept of politicisation of the public debate is difficult to compare with existing measures that either serve as public opinion measures or salience measures. Nevertheless, in the comparison (see further below), we expect to observe some coevolution of politicisation of the public debate with Google Trends and particularly with Gallup's $M I P$, as it is survey-based and thus closer to public opinion but asks respondents directly about salient issues.

\section{Demand measures for the comparison}

Public opinion surveys. To validate our demand measures, we compare them with alternative demand measures, particularly survey data and internet search engine request data. As noted above, we will compare this data with US public opinion survey data from two sources in order to assess the validity of our new data coded by means of news media content analysis.

The first measure is the CCTI. This was developed by Brulle et al. (2012). They use a method suggested by Stimson (1999) to cope with 


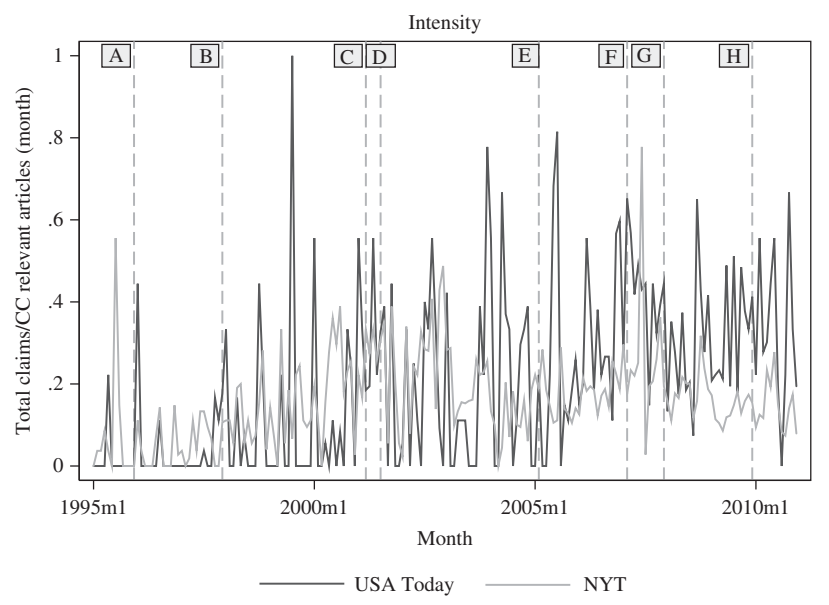

Figure 4 Intensity of the public climate change (CC) discourse, 1995-2010, monthly data.

Note: Measured by total number of claims per month (sum of pro and con claims) divided by the number of CC-relevant articles in USA Today and the New York Times (NYT) (monthly). Scale $=0 \ldots 1$, where " 1 " is the empirical maximum on the variable (occurs in 1999m7). Events: A: assessment report 2 (AR2) (1995m12); B: COP Kyoto (1997m12); C: AR3 and United States resigns of Kyoto (2001m3); D: COP Bonn (2001m7); E: Kyoto Protocol in force $(2005 \mathrm{~m} 2)$; F: AR4 (2007m2); G: COP Bali (2007m12); and H: COP Copenhagen (2009m12).

different surveys that have been implemented over time and that use varying items or item wordings to then estimate a policy mood on climate change. This method uses available survey marginals on questions concerning climate change and relies on a complex algorithm to calculate a comparable metric between those questions. To put it simply, the CCTI can be read as the aggregate survey marginal of all these questions, where higher values represent more concern about climate change. Theoretically, such a policy mood indicator can take values between 0 and 100. In fact, however, the CCTI ranges only between 41.61 and 53.2. It uses 14 survey items and data for a total of 84086 respondents who were polled by six different survey organisations from 2002 to 2010 (Brulle et al. 2012). The CCTI approximates the policy mood concerning climate change on a quarterly basis and can serve as a measure for the opinion component of public demand. As noted above, these are the best approximations of public demand for climate change policies (in which we are ultimately interested) we could find. Nevertheless, as they do not completely capture this concept, we need to remain cautious of this test of our measure as invalidating our approach. Although our new data set covers the years 1995-2010, there is 
no consistent public opinion data on climate policy for the pre-2002 period. Second, to try and overcome this, we use Gallup's MIP item, which is available on a quarterly basis for the entire period (1995-2010). Although it has the best coverage over time, this item is arguably again a very incomplete proxy for public demand for climate change policy. It asks respondents what they consider the most important problems facing the US at the respective point in time. The MIP measure most relevant for us is the proportion of people naming the environment. It can be assigned to the salience aspect of demand and should thus correlate with media salience.

Internet searches. As stated above, internet search data are increasingly relevant to measure the preferences of people. We use Google Trends to compare internet search data with our own demand measures. The original scale of the Google Trends data ranges from 0 to 100, with 100 indicating the national maximum of search requests during the observation period, and 0 indicating the threshold set by Google was not reached. Repeated searches by a single user within a short time are counted as one search. We use data for three search terms "global warming", "climate change" and "greenhouse effect", based on Oehl (2015). The original data have a weekly format and are available from 2004 to present, but we aggregate to monthly data for purposes of comparison here (see Ayoubkhani 2012). As usage of particular search terms may vary over time, we rely on an index proposed by Oehl (2015), which ranges from 0 to 1 .

\section{Comparison}

The main purpose of this article was to find out whether our proposed historical reconstruction of public demand on the basis of media content analysis provides a useful alternative where other types of measures of public demand (notably data from public opinion surveys or internet searches) do not exist, cannot be historically reconstructed or are not commensurable enough to be patched together from different data sets. Although some caveats apply concerning the comparability of the survey measures, we believe this comparison can provide an indication of whether our data represent a valid measure of public demand that can be generalised past the US and whether there are dimensions of public demand where there is more or less overlap.

We thus compare our new data with the best available alternatives namely, public opinion survey data and internet search data from Google Trends. As noted above, the Google Trends data likely capture primarily the saliency dimension of the climate issue, whereas the public opinion data 
tend to capture both saliency and, to some extent, public opinion. The new data are more explicit in measuring media salience, the politicisation of the public debate and published opinion. This raises the issue of what should be compared. We opted for an inductive, data-driven approach and compare the three new measures with both public opinion and internet search data. In order to make our data comparable with the different survey and Google Trends measure, we transformed all series to have a common mean of 0 and a SD of $1 .^{12}$

The following part visually identifies the most obvious similarities and differences, and uses cross-correlation analysis (see Sampei and AoyagiUsui 2009) to obtain some indication of whether and how the series correlate. The latter method reveals patterns of correlation between time series and displays correlations for various lags immediately. If two series move exactly in parallel, we will see a peak at a lag of 0 (contemporaneous). It also enables us to spot lags of one variable that may serve as predictors of the other variable. If two series correlate at lag 0 , this means that we can reject an implicit null hypothesis of independence or noncorrelation between the series. This is in fact what we observe for most of the crosscorrelations examined in the remainder of this section.

\section{Media salience}

As expected, the media salience measure generated by media content analysis seems to perform quite well, presuming that the MIP and Google Trends data are valid indicators of saliency (see Figure 1), and can thus provide the basis for a meaningful comparison (Figure 5, top row). At least until 2007 , the series appear to be quite closely correlated.

In the cross-correlation analysis, we are mostly interested in whether our media salience measure has a high and significant contemporaneous correlation with the target series for salience, the MIP and the Google Trends. ${ }^{13}$ As shown in the bottom row of Figure 5, we can see that the serial cross-correlation between the Google Trends monthly data and our media salience measure is always very high (above 0.6). The Gallup MIP as a survey measure also seems to compare well with our media salience measure, although the contemporaneous correlations are somewhat lower, peaking at around 0.34 . Given that the available data relate only to "the environment" and not to "climate change" or "global warming" as such,

12 That is, for each of the values, the sample mean was subtracted and the result was then divided by the standard deviation of the series.

${ }^{13}$ Significant correlations, indicated by bars to the left (lagging) or to the right (leading) of the 0 line, show whether one variable either leads, meaning that lags of $x$ could serve to predict $y$ at time $t$, or lags the other variable, meaning that leads of $x$ could serve to predict $y$ at time $t$. 

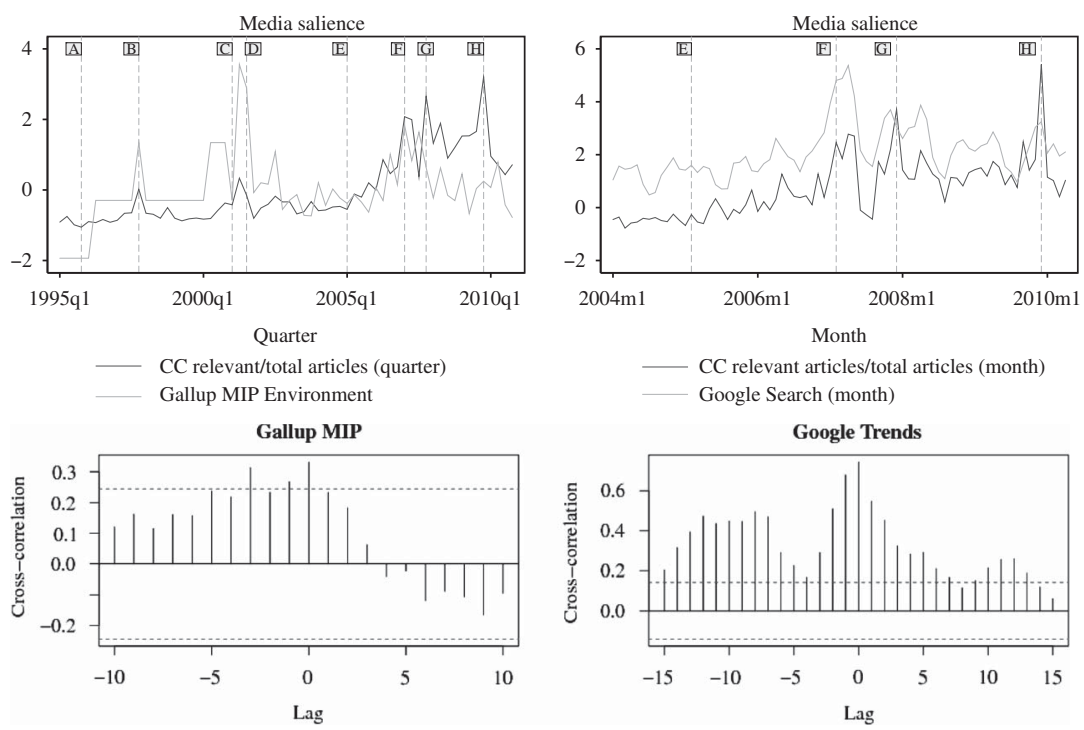

Figure 5 Comparison and cross-correlation of saliency data with survey and internet search data.

Note: Top row: comparison of the relative frequency of media reporting on climate change by two United States (US) newspapers with the Gallup most important problem (MIP) measure and Google Trends data. Scale: normalised with mean $=0$ and $\mathrm{SD}=1$. Events: A: assessment report 2 (AR2) (1995q4); B: COP Kyoto (1997q4); C: AR3 and US resigns of Kyoto (2001q1); D: COP Bonn (2001q3); E: Kyoto Protocol in force (2005q1); F: AR4 (2007q1); G: COP Bali (2007q4); and $\mathrm{H}$ : COP Copenhagen $(2009 q 4)$. Bottom row: cross-correlation coefficient plus $95 \%$ confidence intervals between Gallup MIP and Google Trends and our salience measure [lags in quarters: 10 (Gallup); lags in month: 15 (Google Trends)]. For the cross-correlation analysis, we try to show the cross-correlations over a sufficient number of times, given the length of the time series; we have thus opted to show roughly between one and two years' worth lags.

this may explain the lower cross-correlation. Furthermore, besides the contemporaneous correlations, we can observe that a four-period (one year) lag of the Gallup MIP seems to be a good predictor of our media salience measure at time $t$, meaning the Gallup MIP leads our media salience measure. Overall, we can quite confidently establish that our salience measure can serve as a valid proxy.

\section{Published opinion}

In determining which measures are comparable, we have argued that the opinion dimension (see Figure 1), which we intend to cover with our 

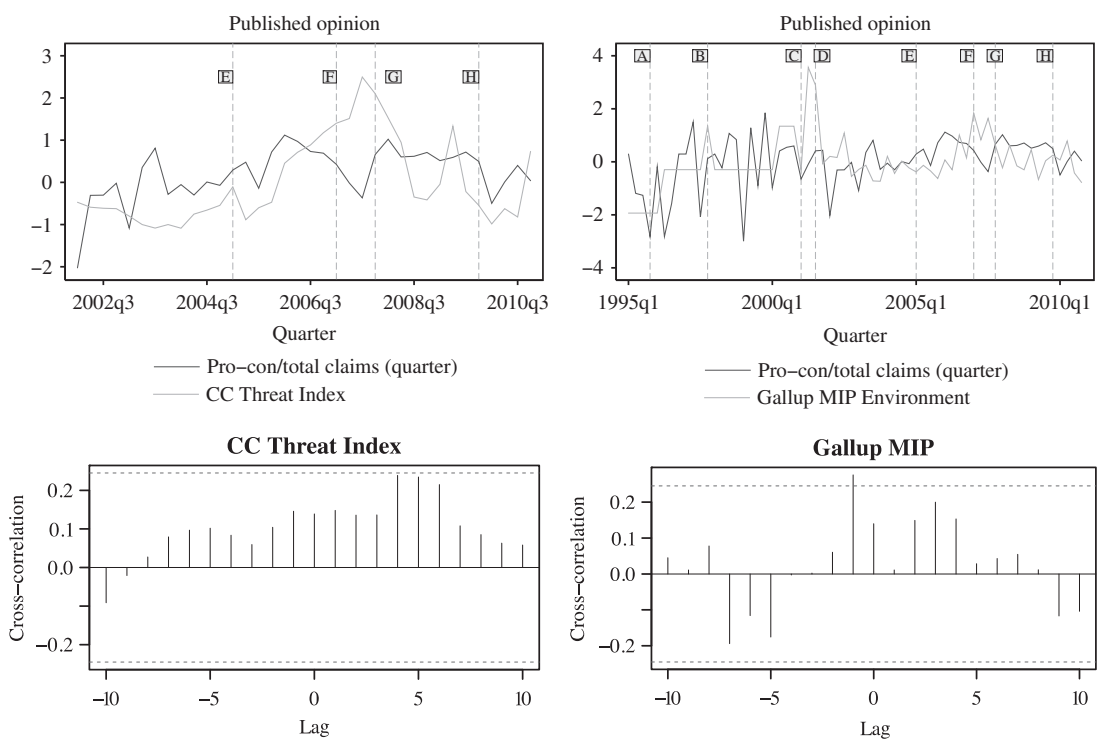

Figure 6 Comparison and cross-correlations of opinion data with survey and internet search data.

Note: The top row compares the ratio of positive to negative claims in media reporting on climate change (CC) by two United States (US) newspapers with the climate change threat index (CCTI) and the Gallup most important problem (MIP) measure. Scale: all series normalised with mean $=0$ and $\mathrm{SD}=1$. Events: A: assessment report 2 (AR2) (1995q4); B: COP Kyoto (1997q4); C: AR3 and US resigns of Kyoto (2001q1); D: COP Bonn (2001q3); E: Kyoto Protocol in force (2005q1); F: AR4 (2007q1); G: COP Bali (2007q4); and H: COP Copenhagen (2009q4). Bottom row: cross-correlation coefficient plus $95 \%$ confidence intervals between CCTI and Gallup MIP and our opinion measure [lags in quarters: 10 (CCTI and Gallup)].

published opinion indicator, can best be compared with the two survey measures (CCTI and MIP). Overall, as shown in Figure 6, it appears that our opinion indicator indeed lines up to some extent with the two surveybased measures. This suggests that the published opinion measure based on the pro/con claims ratio is actually closely linked to the general direction of public opinion concerning climate policy. We observe a generally good fit for both of the survey-based measures, but also observe major differences in published opinion around major events or major amplitudes (positive and negative).

The cross-correlation (bottom row) analysis confirms these visual impressions. The opinion measures against which we compare our published opinion measure are the CCTI and the Gallup question (MIP). 
Although there seems to be no significant correlation for the CCTI and our opinion measure, we observe a significant, although small (0.27), correlation at lag -1 between published opinion and the Gallup MIP (Figure 6). This indicates that a one-period lag of the Gallup MIP $(t-1)$ is a good predictor of our published opinion measure at time $t$, and thus the Gallup MIP leads our opinion measure.

We find two potential reasons for these mixed results. On the one hand, the three alternative measures for public demand available tend to primarily capture concern about climate change issues, and not so much public demand for or against political responses to the problem (our substantive interest). We believe that our opinion measure comes closer to measuring the opinion aspect of public demand than the three best available alternatives used here. However, further research should investigate in greater detail how our measure relates to the very few survey items seeking to capture attitudes towards climate policy more directly. On the other hand, the low cross-correlation could also be due to the fact that editorial policies are producing differences in our opinion measure across media outlets.

\section{Politicisation of public debate}

Finally, as indicated by Figure 7, our measures referring to the politicisation or contestation of an issue lines up quite well with the amplitudes, trends and peaks of the survey data and the internet search data. As this measure conceptually and empirically covers the middle ground between salience and opinion (see Figure 1), we have argued above that the best measures to compare are Gallup MIP and Google Trends.

The cross-correlation (bottom row) analysis supports the visual impression of the comovement of the series. The contemporaneous correlations between the Gallup MIP and the Google Trends and our politicisation of the public debate measure are significant and substantial. It is noteworthy that the Gallup MIP measure, which we think is the most plausible alternative measure for politicisation as it asks for the importance of the topic on the political agenda, correlates significantly and consistently with our politicisation measure. Put differently, the perception of an issue as an important problem seems to go hand in hand with the politicisation of the debate. Regarding the Google Trends measure, we can see that our politicisation measure at time $t-1$ is a good predictor of the Google Trends measure at time $t$, meaning that the Google Trends measure leads our politicisation of the public debate measure. It also makes intuitive sense that an increased politicisation of an issue within the media leads people to search for it. 

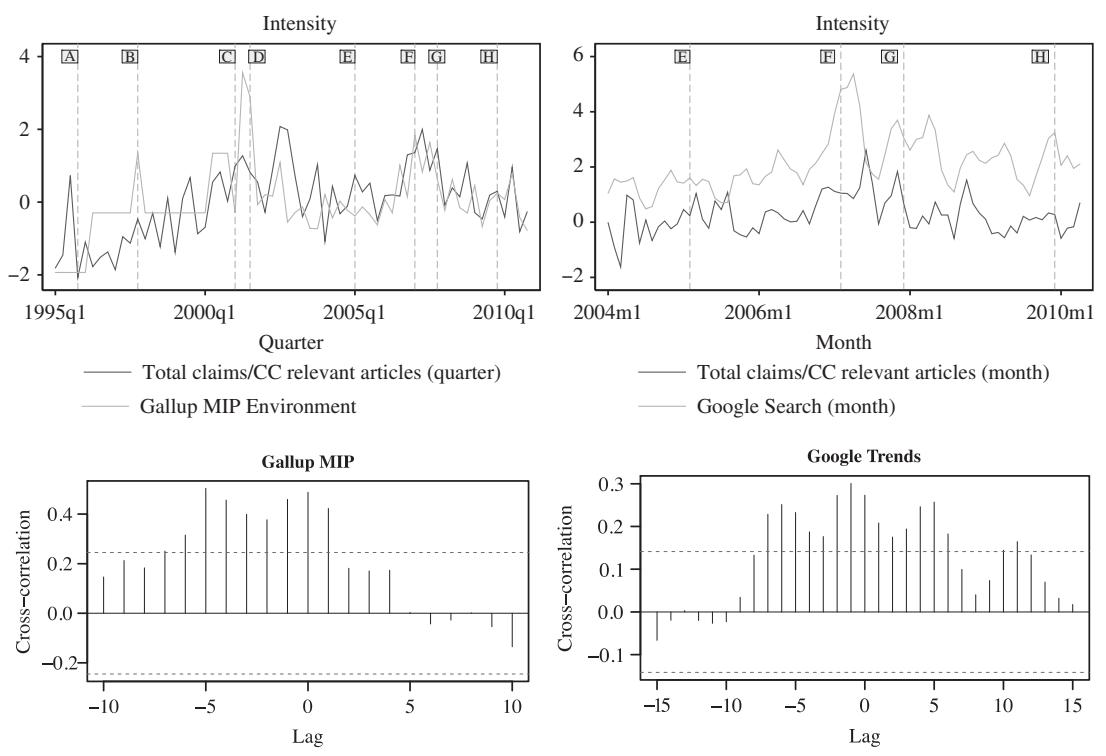

Figure 7 Comparison and cross-correlation of intensity data with survey and internet search data.

Note: The three panels compare the ratio of total claims (positive and negative) with total climate change (CC)-relevant articles two United States (US) newspapers with the climate change threat index (CCTI), the Gallup most important problem (MIP) measure and Google Trends data, respectively. Scale: all series normalised with mean $=0$ and $S D=1$. Events: A: assessment report 2 (AR2) (1995q4); B: COP Kyoto (1997q4); C: AR3 and US resigns of Kyoto (2001q1); D: COP Bonn (2001q3); E: Kyoto Protocol in force (2005q1); F: AR4 (2007q1); G: COP Bali (2007q4); and H: COP Copenhagen (2009q4). Bottom row: cross-correlation coefficient plus 95\% confidence intervals between Gallup MIP and Google Trends and our intensity measure [lags in quarters: 10 (Gallup); lags in month: 15 (Google Trends)].

\section{Robustness check: how does the US case compare with other countries?}

This article has proposed a way of measuring different dimensions of public demand for public policy, focussing specifically on the issue of climate change policy. One reason for our efforts to come up with a media-based content analysis was that commensurable and comparable public opinion or stakeholder survey data between countries and over time are hard to find. Although we have collected our media-based data for six countries over the time period from 1995 to 2010, we were not able to find sufficiently comparable survey data for reliability checks on our data in countries other than the US. However, as a robustness check, this section 
will first show how our US newspaper data compare with our media-based data from Germany ${ }^{14}$ and Spain, ${ }^{15}$ and, second, will compare our data on the public demand for climate change policies to the best available proxies from Germany and Spain. This should increase the confidence that the US case can be regarded as representative of our larger population.

Figure B1 in Appendix B shows our three measures - media salience, published opinion and politicisation of the public debate - for the US, Spain and Germany. In the case of media salience (Panel A), the descriptive comparison of the three time series shows that - generally, but especially since 2005 - the salience for climate change has increased in all three countries, which coincides with the inception of the Kyoto Protocol. Similar to the US case, media salience in Germany has also been elevated sharply from about 2005 onwards. With regard to our published opinion measure, we observe that, although there is a lot of comovement of the three series, published opinion in Germany seems to include more pro claims on average and also more claims in general (see lower part of the graphs in Panel B). Yet, the number of claims sharply increased in all three countries from about 2007 onwards. The third measure, politicisation of the public debate, however, increases over time in the US and stays around the same level in Spain and Germany. This could imply that problems of climate change and potential policy solutions were debated earlier in Spain and Germany compared with the US. All in all, the US case does not differ starkly from the evolution of public demand in climate change leader countries such as Germany, or in other countries that are part of the Kyoto Protocol, such as Spain.

Are our new measures in these two additional countries correlated with the best available proxies concerning public opinion or salience towards climate change? To this end, we again compare our three measures with two different time series: first, the equivalent of Gallup's MIP question on "the environment" surveyed in Germany (Breunig 2014) and Spain ${ }^{16}$ (Chaqués-Bonafont and Baumgartner 2013; Chaqués-Bonafont et al. 2015) ${ }^{17}$ and, second, Google Trends data on internet searches in Germany and Spain.

${ }^{14}$ Coding is based on the two newspapers - Frankfurter Allgemeine Zeitung and Sueddeutsche Zeitung (see the Appendix for more information).

${ }^{15}$ Coding is based on the two newspapers - El Pais and El Mundo (see the Appendix for more information).

16 Originally asked as "Problemas principals que existen actualemente en ESPAÑA". In this case, the category provided asks respondents explicitly for environmental problems, thus not for climate change per se "Medio ambiente (contaminación, degradación del medio ambiente, escasez de aguas, etc.)".

${ }^{17}$ We thank the German (Breunig 2014) and Spanish teams (Chaqués-Bonafont \& Baumgartner 2013; Chaqués-Bonafont et al. 2015) of the Comparative Agendas Project for sharing their quarterly data with us. 
With regard to the respective cross-correlations for our media salience measure, we find that, similar to our US data, the Google Trends data show a significant contemporaneous correlation ranging from 0.4 in Spain to 0.65 in Germany (cf. Figure B2 in Appendix B). Concerning Gallup MIP, for Germany as well as for the US, the contemporaneous correlation is significant (cf. Figure B3 in Appendix B). However, for Spain, the two time series are not seemingly correlated. Furthermore, our measures of published opinion and politicisation do not correlate as well as the media salience measure (see Figures B4-B7 in Appendix B). However, given that the available data relate only to "the environment", and not to "climate change" or "global warming" as such, this may explain the lower cross-correlation.

In sum, the descriptive analysis of our media-based data in three countries finds a lot of parallel movement across all three measures. In comparison with already-existing (but not completely comparable) data, our measure of media salience empirically performs best. The other theoretically important dimensions of public demand we have proposed, published opinion and the politicisation of the debate, do not compare as well. Their importance lies in the potential to use these more fine-grained and multifarious demand measures to explain a government's responsiveness.

\section{Conclusion}

Systematic measurement of public demand for particular policies is important not only normatively, but also analytically, as it is needed to construct accurate explanations of political choices and their outcomes. Public opinion survey data, which presumably offer the most valid information on public demand, are largely unavailable for extensive time periods in forms that allow for crossnational comparison. As these limitations are impossible to overcome post hoc, we investigated whether media content analysis could generate valid proxies for public demand by capturing published opinion. The empirical application focussed on climate change policy.

We coded new media-based public demand data for the time period 1995-2010. To assess the usefulness of our data for researchers trying to build public demand into explanatory models of public policy choices, we generated three types of indicators of public demand - media salience, published opinion and the politicisation of public debate. We subsequently compared these indicators with three alternative measures. Two of these alternatives are based on survey data (CCTI, Gallup's MIP); the third measure is based on internet search data (Google Trends). The comparison focussed on the US as alternative data, and especially data covering the substantive issue area of climate change, are by a wide margin most 
comprehensive for that country. This is especially due to the CCTI, which shows the policy mood specifically for our topic of interest - climate change. However, we also conducted robustness checks by focussing on two more countries, Germany and Spain, to explore the usefulness of our measurement approach and data beyond the US. These additional analyses showed that our approach works quite well for other countries as well, although systematic comparison with alternative measures of public demand is difficult because public opinion data on climate change are very much limited.

The comparisons also show that it is meaningful to disaggregate the spectrum of public demand into specific theoretical concepts (salience and opinion). In particular, the empirical measures for media salience and politicisation line up quite well with the existing survey and internet search data. The published opinion measure shows the lowest cross-correlation scores. However, this is potentially due to the fact that the two alternative measures of public demand tend to primarily capture the attention to, or concern about, climate change issues, and do not link these aspects with public demands in favour or against political responses to the problem (which is what our claims measure). We believe that our opinion measure comes closer to measuring the opinion aspect of public demand than the available alternatives. Nevertheless, further research should investigate in greater detail how our measures relate to those very few survey measures that seek to capture attitudes towards climate policy more directly.

Overall, we submit that the data generation method proposed in this article can produce valid data on public demand for specific policies, notably because it uses information sources political decisionmakers turn to as well when trying to gauge the "public mood". Of course, reliability remains an issue when relying on human coding, although we took the usual precautions such as systematic coder training and coder meetings, as well as random tests for consistency. With rapidly improving technologies for machine-assisted data coding and "big data" approaches to retrieve information from the internet, the problem of reliability and the costs of implementing media content coding are likely to decrease substantially (see e.g. Young and Soroka 2012). Although automated coding may turn out to be very difficult in policy areas that are multifaceted in nature, such as climate policy, it is likely to become a cost-efficient way of coding valid and reliable public demand data in areas where policies are clearly defined and relatively homogeneous or one-dimensional in nature (e.g. military spending, abortion, death penalty, welfare spending). In any event, compared with the costs of public opinion surveys, the approach we propose in this article is much cheaper and can generate high-frequency data, whereas even the most intense (and extremely expensive) public opinion survey efforts (e.g. by Gallup) generate monthly or quarterly data at best. 


\section{Acknowledgements}

We would like to thank Alba Mohedano Roldán, Basil Schläpfer, Brittany Rodriguez, Nicole Ponta, Pascal Scheiwiller, Pia Struntz, Samantha Suarez, and Sara Eliason for their excellent research assistance. We also thank two anonymous reviewers for helpful comments.

\section{Supplementary material}

To view supplementary material for this article, please visit http://dx.doi. org/doi:10.1017/S0143814X16000155

\section{References}

Ahchong K. and Dodds R. (2012) Anthropogenic Climate Change Coverage in Two Canadian Newspapers, the Toronto Star and the Globe and Mail, from 1988 to 2007. Environmental Science and Policy 15(1): 48-59.

Andrewsa K. T. and Caren N. (2010) Making the News: Movement Organizations, Media Attention, and the Public Agenda. American Sociological Review 75(6): 841-866.

Ayoubkhani D. (2012) An Investigation Into Using Google Trends as an Administrative Data Source in ONS. Paper presented at the Conference of European Statisticians, Seminar on New Frontiers for Statistical Data Collection, Geneva, 31 October-2 November, pp. 1-11.

Bättig M. B. and Bernauer T. (2009) National Institutions and Global Public Goods: Are Democracies More Cooperative in Climate Change Policy? International Organization 63(2): 281-308.

Bernauer T., Jahn D., Kuhn P. M. and Walter S. (2014) Einführung in die Politikwissenschaft. Baden-Baden: Nomos.

Bernauer T., Kalbhenn A., Koubi V. and Spilker G. (2010) A Comparison of International and Domestic Sources of Global Governance Dynamics. British Journal of Political Science 40(3): 509-538.

Bernauer T. and Schaffer L. (2012) Climate Change Governance. In Levi-Faur D. (ed.), The Oxford Handbook of Governance. Oxford: Oxford University Press, 441-454.

Boykoff M. T. (2007) Flogging a Dead Norm? Newspaper Coverage of Anthropogenic Climate Change in the United States and United Kingdom from 2003 to 2006. Area 39(4): $470-481$.

Boykoff M. T. and Mansfield M. (2008) "Ye Olde Hot Aire": Reporting on Human Contributions to Climate Change in the UK Tabloid Press. Environmental Research Letters 3(2): 1-8.

Brechin S. R. and Bhandari M. (2011) Perceptions of Climate Change Worldwide. Wiley Interdisciplinary Reviews: Climate Change 2(6): 871-885.

Breunig C. (2014) Content and Dynamics of Legislative Agendas in Germany. In Green-Pedersen C. and Walgrave S. (eds.), Agenda Setting, Policies, and Political Systems. Chicago, IL: University of Chicago Press, 125-163.

Brewer T. L. (2005) US Public Opinion on Climate Change Issues: Implications for ConsensusBuilding and Policymaking. Climate Policy 4(4): 359-376.

Brossard D., Shanahan J. and McComas K. (2004) Are Issue-Cycles Culturally Constructed? A Comparison of French and American Coverage of Global Climate Change. Mass Communication and Society 7(3): 359-377. 
Brulle R., Carmichael J. and Jenkins C. (2012) Shifting Public Opinion on Climate Change: An Empirical Assessment of Factors Influencing Concern Over Climate Change in the U.S., 2002-2010. Climatic Change 114(2): 169-188.

Burstein P. (2003) The Impact of Public Opinion on Public Policy: A Review and an Agenda. Political Research Quarterly 56(1): 29-40.

Burstein P. (2006) Why Estimates of the Impact of Public Opinion on Public Policy are Too High: Empirical and Theoretical Implications. Social Forces 84(4): 2273-2289.

Carvalho A. and Burgess J. (2005) Cultural Circuits of Climate Change in U.K. Broadsheet Newspapers, 1985-2003. Risk Analysis 25(6): 1457-1469.

Chaqués-Bonafont L. and Baumgartner F. R. (2013) Newspaper Coverage of Politics in a Partisan Media System. The Case of Spain. Journal of Public Policy 33(1): 65-88.

Chaqués-Bonafont L., Palau A. and Baumgartner F. R. (2015) Agenda Dynamics in Spain. London: Palgrave Macmillan.

Choi H. and Varian H. (2012) Predicting the Present with Google Trends. Economic Record 88: 2-9. Chyi H. I. and McCombs M. (2004) Media Salience and the Process of Framing: Coverage of the Columbine School Shootings. Journalism and Mass Communication Quarterly 81(1): 22-35. Cohen J., Tsfati Y. and Sheafer T. (2008) The Influence of Presumed Media Influence in Politics: Do Politicians' Perceptions of Media Power Matter? Public Opinion Quarterly 72(2): 331-344.

Cook F. L., Tyler T. R., Goetz E. G., Gordon M. T., Protess D., Leff D. R. and Molotch H. L. (1983) Media and Agenda Setting: Effects on the Public, Interest Group Leaders, Policy Makers, and Policy. Public Opinion Quarterly 47(1): 16-35.

Dahl R. A. (1971) Polyarchy, Participation and Opposition. New Haven, CT: Yale University Press. Dasgupta S., Laplante B., Wang H. and Wheeler D. (2002) Confronting the Environmental Kuznets Curve. The Journal of Economic Perspectives 16(1): 147-168.

Davison W. (1983) The Third-Person Effect in Communication. Public Opinion Quarterly 47(1): $1-15$.

Denham B. E. (2014) Intermedia Attribute Agenda Setting in the New York Times: The Case of Animal Abuse in U.S. Horse Racing. Journalism and Mass Communication Quarterly 91(1): 17-37.

Donner S. D. and McDaniels J. (2013) The Influence of National Temperature Fluctuations on Opinions About Climate Change in the U.S. Since 1990. Climatic Change 118(3-4): 537-550.

Downs A. (1957) An Economic Theory of Democracy. Boston, MA: Addison Wesley.

Fisher D. R., Leifeld P. and Iwaki Y. (2012) Mapping the Ideological Networks of American Climate Politics. Climatic Change 116(3-4): 523-545.

Frank D. J. (1999) The Social Bases of Environmental Treaty Ratification, 1900-1990. Sociological Inquiry 69(4): 523-550.

Fredriksson P. G. and Millimet D. L. (2004) Electoral Rules and Environmental Policy. Economics Letters 84(2): 237-244.

Gamson W. A. and Modigliani A. (1989) Media Discourse and Public Opinion on Nuclear Power: A Constructionist Approach. American Journal of Sociology 95(1): 1-37.

Golan G. (2006) Inter-Media Agenda Setting and Global News Coverage. Journalism Studies $7(2): 323-333$.

Google (2014) Where Trends Data Comes From, https:/support.google.com/trends/answer/ 4355213? hl=en (accessed 5 June 2014).

Gunther A. C. (1998) The Persuasive Press Inference: Effects of Mass Media on Perceived Public Opinion. Communication Research 25(5): 486-504.

Gunther A. C. and Storey J. D. (2003) The Influence of Presumed Influence. Journal of Communication 53(2): 199-215. 
Habel P. D. (2012) Following the Opinion Leaders? The Dynamics of Influence Among Media Opinion, the Public, and Politicians. Political Communication 29(3): 257-277.

Herbst S. (1993) Numbered Voices. How Opinion Polling has Shaped American Politics. Chicago, IL: University of Chicago Press.

Herbst S. (1998) Reading Public Opinion: How Political Actors View the Democratic Process. Chicago, IL: University of Chicago Press.

Howland D., Becker M. and Prelli L. (2006) Merging Content Analysis and the Policy Sciences: A System to Discern Policy-Specific Trends from News Media Reports. Policy Sciences 39(3): 205-231.

Jacobs L. R. and Shapiro R. Y. (2000) Politicians Don't Pander. Chicago: University of Chicago Press.

Kahn M. E. and Kotchen M. J. (2011) Business Cycle Effects on Concern About Climate Change: The Chilling Effect of Recession. Climate Change Economics 2(3): 257-273.

Kim S. Y. and Wolinsky-Nahmias Y. (2014) Cross-National Public Opinion on Climate Change: The Effects of Affluence and Vulnerability. Global Environmental Politics 14: 79-106.

Koopmans R. (2004) Movements and Media: Selection Processes and Evolutionary Dynamics in the Public Sphere. Theory and Society 33: 367-391.

Koopmans R. (2007) Who Inhabits the European Public Sphere? Winners and Losers, Supporters and Opponents in Europeanised Political Debates. European Journal of Political Research 46(2): 183-210.

Koopmans R. and Statham P. (1999) Political Claims Analysis: Integrating Protest Event and Political Ciscourse Approaches. Mobilization: An International Quarterly 4: 203-221.

Koopmans R. and Statham P. (2010) Theoretical Framework, Research Design and Methods. In Koopmans R. and Statham P. (eds.), The Making of a European Public Sphere. Media Discourse and Political Contention. Cambridge: Cambridge University Press, 34-62.

Krosnick J., Holbrook A., Lowe L. and Visser P. (2006) The Origins and Consequences of Democratic Citizens' Policy Agendas: A Study of Popular Concern About Global Warming. Climatic Change 77(1): 7-43.

Lakoff G. (2010) Why it Matters How We Frame the Environment. Environmental Communication: A Journal of Nature and Culture 4(1): 70-81.

Lee H. S. (2014) Analyzing the Multidirectional Relationships Between the President, News Media, and the Public: Who Affects Whom? Political Communication 31(2): 259-281.

Luntz F. (2003) The Environment: A Cleaner, Safer, Healthier America. The Luntz Research Companies, Straight Talk. Unpublished Memo, 131-146.

McCombs M. and Shaw D. (1972) The Agenda-Setting Function of Mass Media. Public Opinion Quarterly 36(2): 176-187.

McLeod J. M., Becker L. B. and Byrnes J. E. (1974) Another Look at the Agenda-Setting Function of the Press. Communication Research 1(2): 131-166.

Mellon J. (2014) Internet Search Data and Issue Salience: The Properties of Google Trends as a Measure of Issue Salience. Journal of Elections, Public Opinion and Parties 24(1): 45-72.

Mutz D. (1998) Impersonal Influence. How Perceptions of Mass Collectives Affect Political Attitudes. Cambridge: Cambridge University Press.

Neumayer E. (2002) Do Democracies Exhibit Stronger International Environmental Commitment? A Cross-Country Analysis. Journal of Peace Research 39(2): 139-164.

Neumayer E. (2003) Are Left-Wing Party Strength and Corporatism Good for the Environment? Evidence from Panel Analysis of Air Pollution in OECD Countries. Ecological Economics 45(2): 203-220.

Nisbet M. C. and Myers T. (2007) The Polls - Trends - Twenty Years of Public Opinion About Global Warming. Public Opinion Quarterly 71(3): 444-470. 
Oehl B. (2015) Public Demand and Climate Change Policy Making in OECD Countries - From Dynamics of the Demand to Policy Responsiveness, ETH Zürich Nr. 22537, http:// ecollection.library.ethz.ch/view/eth:47706 (accessed 5 August 2016).

Olson M. (1965) The Logic of Collective Action: Public Goods and the Theory of Groups. Cambridge, MA: Harvard University Press.

Pelc K. J. (2013) Googling the WTO: What Search-Engine Data Tell Us About the Political Economy of Institutions. International Organization 67(3): 629-655.

Perloff R. M. (1993) Third-Person Effect Research 1983-1992: A Review and Synthesis. International Journal of Public Opinion Research 5(2): 167-184.

Persson T. and Tabellini G. E. (2002) Political Economics: Explaining Economic Policy. Boston, MA: MIT Press.

Peter J. and Lauf E. (2002) Reliability in Cross-National Content Analysis. Journalism and Mass Communication Quarterly 79(4): 815-832.

Powlick P. (1995) The Sources of Public Opinion for American Foreign Policy Officials. International Studies Quarterly 39(4): 427-451.

Ripberger J. T. (2011) Capturing Curiosity: Using Internet Search Trends to Measure Public Attentiveness. Policy Studies Journal 39(2): 239-259.

Roberts T. J., Parks B. C. and Vásquez A. A. (2004) Who Ratifies Environmental Treaties and Why? Institutionalism, Structuralism and Participation by 192 Nations in 22 Treaties. Global Environmental Politics 4(3): 22-65.

Sampei Y. and Aoyagi-Usui M. (2009) Mass-Media Coverage, its Influence on Public Awareness of Climate-Change Issues, and Implications for Japan's National Campaign to Reduce Greenhouse Gas Emissions. Global Environmental Change 19(2): 203-212.

Schaffer L. (2011) Voluntary Climate Change Initiatives in the U.S.: Analyzing Participation in Space and Time, ETH Zürich Nr. 19475, http://e-collection.library.ethz.ch/view/ eth:2712?q= (accessed 5 August 2016).

Scharkow M. and Vogelgesang J. (2011) Measuring the Public Agenda Using Search Engine Queries. International Journal of Public Opinion 23(1): 104-113.

Schmidt A., Ivanova A. and Schäfer M. S. (2013) Media Attention for Climate Change Around the World: A Comparative Analysis of Newspaper Coverage in 27 Countries. Global Environmental Change 23(5): 1233-1248.

Spilker G. (2011) Helpful Organizations: Membership in Inter-Governmental Organizations and Environmental Quality in Developing Countries. British Journal of Political Science 42(2): 345-370.

Stamm K. R., Clark F. and Eblacas P. R. (2000) Mass Communication and Public Understanding of Environmental Problems: The Case of Global Warming. Public Understanding of Science 9: 219-237.

Stimson J. A. (1999) Public Opinion in America: Moods, Cycles, and Swings. Boulder, CO: Westview Press.

Sun Y., Pan Z. and Shen L. (2008) Understanding the Third-Person Perception: Evidence from a Meta-Analysis. Journal of Communication 58(2): 280-300.

Vliegenthart R., Schuck A. R. T., Boomgaarden H. G. and De Vreese C. H. (2008) News Coverage and Support for European Integration, 1990-2006. International Journal of Public Opinion Research 20(4): 415-439.

Vliegenthart R. and Walgrave S. (2008) The Contingency of Intermedia Agenda Setting: A Longitudinal Study in Belgium. Journalism and Mass Communication Quarterly 85(4): $860-877$.

Wallsten K. (2007) Agenda Setting and the Blogosphere: An Analysis of the Relationship Between Mainstream Media and Political Blogs. Review of Policy Research 24(6): 567-587. 
Weingart P., Engels A. and Pansegrau P. (2000) Risks of Communication: Discourses on Climate Change in Science, Politics, and the Mass Media. Public Understanding of Science 9(3): 261-283.

Young L. and Soroka S. (2012) Affective News: The Automated Coding of Sentiment in Political Texts. Political Communication 29(2): 205-231.

Zaller J. (1992) The Nature and Origins of Mass Opinion. Cambridge: Cambridge University Press.

Zhao X. (2009) Media Use and Global Warming Perceptions. Communication Research 36(5): 698-723. 